\title{
DEVELOPMENTS IN ASTRONAUTICS
}

$\mathrm{T}$ HOUGHTS on the seminar on "Astronautics", held in the University of Southampton during July 12-19, should be considered against the technology of the changing scene in air and space, an unsteady scene, its movements affected by engineering and scientific inventions. The trend is to curtail weapon programmes, and in place of production quantities there is more limited manufacture of precision 'hardware'; aircraft types are fewer and more highly specialized, benefiting from the development of rocket systems and instrumentation.

The five groups of twenty-three interrelated lectures provided a clear picture of the scientific and technological aspects of the subjects, the result of painstaking planning by those to whom science was an intellectual adventure.

The seminar was organized by the N.A.T.O. Advisory Group for Aeronautical Research and Development and the University of Southampton. Prof. E. J. Richards, head of the first Department of Aeronautics and Astronautics in Great Britain (University of Southampton), introduced Mr. E. T. Jones, deputy director of A.G.A.R.D., who welcomed the delegates, mentioning the fitness of the venue, the first of its kind, due to the enterprise of the professorial staff, particularly Dr. B. L. Clarkson.

Mr. M. J. Lighthill, director of the Royal Aircraft Establishment, gave the introductory lecture to about a hundred delegates from Europe and the United States. Brilliantly he set the scene, introducing the subjects to be discussed; dealing with aims and organization of pure, and applied, space science and technology. Space included the stars, planets, and everything known and predieted by the astronomers, to whom we are indebted for information, and with whom it is most desirable to co-operate.

In pure science we are concerned with perturbations of orbits, macrometeorites in orbit, the fluctuating environment of plasma, solar activity, solar streams, and radiation effects, Van Allen belts, and plasma propulsion.

In applied science we consider geodesy, navigation, transit satellites, observations, communications, geometric aspects of space, meteorology, information for synoptic meteorologists, the particular need for viewing clouds from above-thermal stability in satellites, solar cells, gyroscopes, and generally the application of discoveries useful for mankind. For the future, Blue Streak and Black Knight would help in the further observation of the ionosphere and re-entry research as well as contributing to the communication satellites plan, now being handled by the Royal Aircraft Establishment and the General Post Office, the Commonwealth and the European Space Launcher Organization; this scheme is promising and will engender greater integration, economical development, technical adventure and co-operation over a wide field, and would attract the best men. The co-operative scheme needs intensive planning for arranging the work, and a body to co-ordinate effort from design to the operating conditions. This includes using existing institutions, avoiding extravagances, and avoiding the separation of aerodynamies, astronautics and space technology.
Useful visits were made to the Royal Aircraft Establishment, the Radio Research Establishment, and the Royal Greenwich Observatory.

"Orbits in the Solar System" was the subject of a lecture by Dr. J. G. Porter, Royal Greenwich Observatory, and he was followed by Mr. D. G. King-Hele, Guided Weapons Department, Royal Aireraft Establishment, with a paper on "EarthSatellite Orbits".

These papers dealt with orbits affected by perturbations. As an astronomer, Dr. Porter was concerned with all the members of the solar group and their movements in continuously variable ellipses, and the method of defining the instantaneous orbit in which a body is travelling at a given epoch. The figures in the published ephemerides of the Sun and planets are based on rectangular co-ordinates measured in astronomical units to seven decimal places; they are published so that observers may make a comparison with theory. Tables of planetary co-ordinates for the next twenty years are available, and for Mars for every four days up to 2,000.

Complementary to Dr. J. G. Porter's talk, Mr. D. G. King-Hele dealt in more detail with four main perturbations affecting the orbit of a satellite, caused by: (1) the departure of the Earth's gravitational field from spherical symmetry; (2) the influence of atmospheric drag; (3) the luni-solar gravitational attractions; and (4) solar radiation pressure. Near satellites, having a perigee height of less than 1,000 $\mathrm{km}$., and apogee heights of less than $5,000 \mathrm{~km}$., are affected particularly by 1 and 2 . The third perturbation results from the asymmetry between the northern and southern hemispheres. If the apogee height of a satellite is greater than $20,000 \mathrm{~km}$. (Explorers 5 and 10) the gravitational attractions of the Sun and Moon are important in addition to those already mentioned, and if the perigee height exceeds $1,000 \mathrm{~km}$. the force due to solar radiation pressure is greater than atmospheric drag.

Prof. T. R. F. Nonweiler, Mechan professor of aeronautics and fluid mechanics, Unjversity of Glasgow, spoke on "Re-entry Orbits", discussing the two conditions in which re-entry will occur, either as the final result of the gradual contraction of the orbit by air resistance, or by deliberate perturbations (through the action of retro-rockets). The speed at the first stage of re-entry, say Mach 30, is changing to stage two at Mach 3 or 4 , then to stage three at Mach $0 \cdot 3-0 \cdot 2$, and finally the vertical drop. While drag can be reduced, it is not possible to reduce the rate of heating, and this problem at hypersonic speeds has two satisfactory solutions, namely, ablation, and variable drag by flared skirt or parachute. When retro-rockets are used to control the vehicle, the point of firing is important so that the vehicle hits the target. Whatever the shape of the vehicle the maximum deceleration is the same, but it occurs at a greater height if the design is blunt and is of high drag; thus in the lower part of the atmosphere a blunt satellite has a lower speed and endures less heating. A more streamline and fasterfalling vehicle suffers intense heating in the denser part of the atmosphere where maximum deceleration 
occurs. If the vehicle can be given some aerodynamic lift to modify the re-entry path, then the rate of heating and deceleration can be reduced.

Captain P. V. H. Weems, U.S. Naval Academy, rounded off the session on orbits by explaining his method of "Space Navigation". The basic concept is that the space observer's optical line of sight to the Earth's centre is in the observer's vertical. Range is restricted to cislunar navigation and the spacevehicle is assumed to have sufficient power to enable it to be directed and navigated. The Earth is used: (1) for fixing the position of the space observer's geographical position by observing visually the position of the Earth's centre relative to the stars; (2) for finding the distance from the Earth's surface stadimetrically by using the Earth's diameter as a base; (3) for guiding a space-vehicle by so changing its velocity as to cause the apparent path of the Earth's centre to follow a precomputed path. The space navigator can fix the relative position of the satellite by using a two-way telescope, which would provide, simultaneously, fixes on the Earth's centre and the zenithal stars, and then tables will give the position. The proposed Space Almanac has been started, by attempting to provide a space navigator for the Eicho satellite with usable data, and it is intended for teachers and students one or two generations ahead of the astronaut.

Prof. E. Vassy, of the University of Paris, in discussing "Physical Properties of the Upper Atmosphere", paid due tribute to the astronomers, and outlined the results from the Veronique research rocket, the programme being similar to that of the Skylark, there being close collaboration with the Royal Aircraft Establishment in the development of the mass spectrograph for ion measurement.

Prof. B. Fraeijs de Veubeke, University of Liège, discussed the "Optimization of Space Vehicles and Launchers relative to their Missions", and showed that minimization of fuel consumption, initial weight, initial thrust for a given payload and given performance requirements lead to widely different missile configurations; and then there is the extensive analysis necessary to determine the minimization of cost of mission per unit payload.

Prof. L. Broglio, Department of Aeronautics, University of Rome, explained "A Method for Solving Non-linear Thermal Problems in the Re-entry of Space Vehicles".

In "Some Recent Advances in the Theory of Control", Dr. J. K. Lubbock, University of Cambridge, assessed the progress of control theory embracing non-linear systems, and dealt with tho difficulties of analysis and optimization of feedback systems containing non-linear elements. He reviewed the Fokker-Planck equation for the Markov processes; he believes that Pontryagins' general theory is the most significant theoretical advance in recent years.

Dr. W. W. Lines, Guided Weapons Department, Royal Aircraft Establishment, outlined the "Problems of Guidance in Astronautics" and dealt with methods for the injection of Earth satellites into orbit, and the problem of orbital transfer.

Flight-Lieutenant J. C. Guignard, Institute of Aviation Modicine, discussed "Physiological Limitations of Man in Space". He said that from the physiological aspect, space begins at sea-level, and the basic problems extend to meet the conditions discussed in the seminar are being studied in simula. tion laboratories. The absence of normal diurnal and seasonal cycles during flights of weeks or months demands new knowledge.

Dr. E. V. D. Glazier, Royal Radar Establishment, discussed the radio problems for interplanetary space probe missions where the range may be many millions of miles, but at present there are limitations on probe transmitter power and life, and on the extent of costly ground facilities. Measurement of range is achieved by the secondary radar principle, and good tracking in range and angle can be obtained out to ten million miles with a slight extension of present techniques. For reciprocal and rapid transmission during a Venus mission, more powerful transmitters and aerials of the Jodrell Bank type are essential.

In a paper on "Hypersonic Aerodynamics", Mr. K. M. C. Bray, University of Southampton, said that perfect fluid hypersonic effects, real gas effects and high-altitude effects are three classes of problem that may occur simultaneously, but they must be studied. separately in order to provide information for the design of the blunt-nosed ballistic vehicle or the slimmer boost glider type. The designer needs to know the heat-transfer rate at the stagnation point, perhaps in the presence of ablation, then data about drag and dynamic stability. Due to the Faraday effect, under hypersonic conditions radio signals to a vehicle suffer serious interference.

Complementary to Mr. K. M. C. Bray's paper was "Laboratory Facilities and Techniques for Rarefied Gasdynamics Research", by Mr. R. L. Chuan, director, Engineering Centre, University of Southern California, who stressed the need for more advanced designs of experimental apparatus to analyse the problems raised by Mr. Bray. Four types of facilities of various degrees of complexity and cost are needed: the wind tunnel, shock tubes, molecular beam, and the rotating arm. The study of hypersonic phenomena requires conditions in air of Mach number greater than 10, a Reynolds number less than 100, and a static temperature of about $300^{\circ} \mathrm{K}$. Pressure, temperature, density, speed, gas composition are basic quantities to be measured, the pressure being of the order of $10^{-6} \mathrm{~atm}$; ; and this Mr. Chuan had achieved by designing a low-density hypersonic tunnel around a cryopump cooled by a helium refrigerator achieving $20^{\circ} \mathrm{K}$.

Mr. D. J. Johns, College of Aeronautics, reviewed the design of the thin cylindrical structures typical of the liquid-fuelled launching vehicles, covering all the ground handling and flight conditions until impact on landing. They included pressurization, axial and lateral loads, thermal, dynamic and space environment offects. In general, the pressure-stabilized structure is lighter and simpler than the convention. ally stiffened type. The inflatable structure has minimum structural density, maximum volume/ weight ratio, and unmatched packageability for the launch phase. Prof. A. J. Murphy, principal of the College of Aeronautics, spoke about the nature of the environment in outer space, and its significance for "Materials for Astronautic Vehicles", and said that the requirements discussed by $\mathbf{M r}$. D. J. Johns could be met by the use of metals of higher melting point, especially beryllium, molybdenum, columbium and tungsten, and also non-metals such as carbon, ceramics, or metal-ceramic mixtures. Refractory metals withstand $1,370^{\circ} \mathrm{C}$. at stressed conditions but need protection against oxidation. Heat-dissipating ablation surfaces of organic material are satisfactory. 
Prof. E. J. Richards (Southampton) discussed "Some Problems of Noises in Ballistic Missiles", briefly sketching the effect of noise-levels on structures and instruments between 100 and 180 decibels; at 140-150 db. structures begin to crack, and at $170 \mathrm{db}$. cracking is immediate. To guard against trouble, there must be a detailed analysis of the environment of noise around a vehicle both during launching and at re-entry. The source of most efflux noise of a rocket is about eighteen diameters downstream, the unsteady conditions with fluctuating pressures arising from turbulent mixing of the gas in the jet, from the rough flow in the boundary layer, and from the movement of the missile in turbulent air; fluctuating shock waves buffet the missile. Noise may bo real and radiated acoustically or as hydrodynamic pressure fluctuations exciting the structure and causing acoustical radiation inside it.

Mr. G. K. C. Pardoe, chief weapons research engineer, De Havilland Co., spoke on "Space Flight Projects based on Blue Streak". His practical outlook brought together the theoretical and design philosophies discussed in other papers. Blue Streak will have a fundamental part in the proposed research work on probes, satellite communication and meteorology, and this activity means that the European Space Launcher Organization should get off to a good start. Mr. Pardoe reviewed the Eslo three-stage launcher based on Blue Streak, with a second stage of French design. Various third stages have been proposed and could produce high or low thrust, depending on the kind of mission; Black Knight with Bristol Siddeley Gamma engine would give a versatile performance. Mr. C. R. Turner, of the De Havilland Co., spoke on "Communication Satellites", describing a world-wide coverage scheme based on Blue Streak.

Prof. P. C. Parkes, Control Engineering Department, University of Southampton, speaking in Russian, welcomed Prof. A. M. Bobrov, chief scientist, Astronomical Society, Academy of Sciences, U.S.S.R., who discussed the "Cosmological Neighbours of the Earth" from the astronomer's point of view, referring to the Sun, and the atmosphere of the Moon, Venus and Mars. Astrobiological laboratories are growing plants under simulated Martian conditions. A third belt of radiation has been located beyond the Van Allen belts.
Dr. R. R. Jamison, assistant chief engineer (ramjets), Bristol Siddeley Engines, Ltd., in discussing "Advanced Air-breathing Engines", said that the use of these engines for astronautical work was as propulsion units for space-vehicles during the boost phase of space missions. Studies based on development work show that the ramjet has a better fuel specific impulse than a typical rocket engine and so should be $a$ better first-stage booster, faster and lighter. It must operate up to speeds which are a significant proportion of orbital velocity, and research indicates that speeds much higher than the present operable Mach 6 can be achieved.

Mr. S. L. Bragg, chief scientist, Rolls Royce, Ltd., discussed "Operation and Control of Liquid Propellant Rocket Engines", and explained the difficult handling problems of starting, keeping the engine running, and stopping. The Blue Streak ongine is the $R Z$-2, using liquid oxygen and kerosene. Accurate control of the moment at which the engine is shut down is essential to enable the accelerating vehicle to follow the flight plan. After the stopping signal, there will be a brief time while the engine runs down, and on a multi-stage rocket it is desirable that the thrust should cease before the stages separate to avoid the possibility of subsequent collisions.

Mr. P. A. F. Stewart, rocket and satellite systems engineer, Hawker Siddeley Aviation, Ltd., in dealing with "Advanced Propulsion Systems for Space", reviewed the three main classes: $(a)$ high acceleration, covering free-radical rocket propulsion; open-cycle thermonuclear propulsion, and ionospheric recombination ramjets; (b) for medium acceleration there is solar energy; and $(c)$ for low acceleration the closed-cycle nuclear system and variations of the electrodynamic types, electro-thermal or are-jet, electrostatic or ion engine, the magnetohydrodynamic type, and the photon system.

Group (c) attracted most interest; progressive laboratory work has been achieved in electrical propulsion and the arc-jet is well advanced. Electric propulsion provides jet velocities 5-10 times those of nuclear engines, but as the thrusts are limited to pounds and fractions of a pound, they are promising only in space flight; but the problems are chemical and mechanical. Then there is the question of spaceflight test-beds.
A. Cadman Cunnton

\section{THE COLONIAL DEVELOPMENT CORPORATION}

\section{Annual Report, 1960}

$\mathrm{T}$ HE annual report and statement of accounts of the Colonial Development Corporation for the year ended December 31, 1960, the first to appear over Lord Howick's signature, who, as chairman, succeeded Sir Nutcombe Hume on December 1, 1960, follows the pattern of recent reports*. Ninety-one continuing projects are reported as compared with 88 in the previous year, including 10 now projects totalling $£ 11,675,000$. Seven projects have been removed from the list and total commitments aggregated $£ 109,448,000$ compared with $£ 96,145,000$ in 1959. Of this aggregate, $£ 14 \cdot 6$ million was in the

* Colonial Development Corporation. Annual Report and Statement of Accounts for the year ended 31st December, 1960. Pp. vi +82 . (London: H.M.S.O., 1961.) 58, net.
Caribbean; $£ 19.4$ million (including $£ 12.8$ million for the Federation of Malaya) in the Far East; $£ 22.7$ million in East Africa; $£ 22.0$ million in Central Africa; $£ 16.0$ million in the High Commission Territories; and $£ 14 \cdot 7$ million (including $£ 205,000$ in Ghana and $£ 8.9$ million in the Federation of Nigeria). Functionally 52.5 per cent of the committed capital was for basic development, 38.3 per cent for primary production and processing, and $9 \cdot 2$ per cent for commerce and industry.

The report is at pains to emphasize the nature of the Corporation's task and some of its achievements in Africa. It is believed that the Corporation can make an important contribution to the economic life of the emerging peoples for several reasons. Its regional organizations have now been established for nearly ten years and its employees are able to 